\title{
Pancarditis affecting the conducting system and all valves in human African trypanosomiasis
}

\author{
A. A. Poltera, ${ }^{1}$ J. N. Cox, and R. Owor \\ From the Departments of Pathology, Makerere University, Kampala, Uganda; and University of Geneva, \\ Switzerland
}

This paper describes the pathological features of 10 cases of human African trypanosomiasis occurring in Uganda over an 8-year period. Three cases were clinically proved, and in all 10 cases chronic meningoencephalitis and myocarditis were present. There was chronic pancarditis in 6 cases, and in 3 of these there was a generalized focal valvulitis and in 2 lesions of the conducting system.

Previous descriptions of carditis in human African trypanosomiasis are briefly reviewed, and the present findings are compared with some cardiomyopathies as well as American human and experimental trypanosomiasis.

Although myocarditis in human African trypanosomiasis is not uncommon, detailed histological reports are rare (World Health Organization, 1969; Mulligan and Potts, 1970). Reports from East Africa have described only clinical (Manson-Bahr and Charters, 1963) and necropsy findings (Hawking and Greenfield, 1941; de Raadt and Koten, 1968; Koten and de Raadt, 1969; Hutt and Wilks, 1971). Similarly, Schyns and Janssen (1955), Bertrand et al. (1967a, b), and Francis (1972) documented the symptomatology of $T$. gambiense myocarditis including electrocardiographic abnormalities. Lavier and Leroux (1939) and Bertrand et al. (1967b) reported on some histological aspects of T. gambiense carditis, but in only 2 cases. We report here 10 cases with particular reference to the cardiac lesions.

\section{Subjects and methods}

The 10 cases of human African trypanosomiasis were investigated at the Department of Pathology, Makerere University, Kampala, Uganda, between 1967 and 1974. Two of the cases were of untreated trypanosomiasis, and both had meningoencephalitis and pancarditis. The hearts in these 2 cases were further studied in the Department of Pathology, University of Geneva, Switzerland. The findings are reported below. Then follows a report of a retrospective study of the remaining 8 cases.

Received 19 November 1975.

'Present address: Clinique universitaire de médecine Hôpital cantonal, $\mathrm{CH}-1211$ Geneva 4-Switzerland.

\section{Case 1}

\section{Two-case study}

A 36-year-old man of the Dama tribe from Eastern Uganda was transferred from a district hospital to Mulago Hospital 10 days before death with a diagnosis of cerebral malaria. He had had fever for 5 days together with headaches, dizziness, and sweating. Before admission to the district hospital

TABLE Cardiac morphological features in human African trypanosomiasis from Uganda

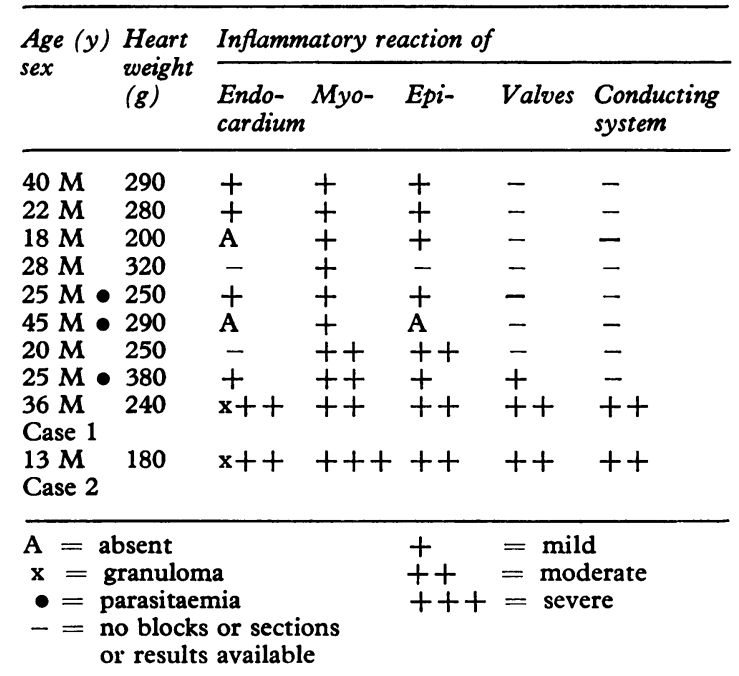


he was unable to walk, sit, or stand or to hold anything in his hands. On admission he was semiconscious, in poor general condition, dehydrated, and febrile at $38^{\circ} \mathrm{C}$. His blood pressure was $110 / 70$ $\mathrm{mmHg}(14 \cdot 6 / 9 \cdot 3 \mathrm{kPa})$. There was no response to chloroquine and the cerebrospinal fluid showed nothing unusual. As the salmonella $\mathrm{H}$-antigen titre was $1 / 400$ he was treated for typhoid fever but without success. He died on the 11th hospital day. Necropsy was carried out 4 hours after death.

Necropsy The patient's weight was $42.6 \mathrm{~kg}$ and height $154 \mathrm{~cm}$. No serous fluids were found. The brain (1250 g) showed a diffuse capillary congestion and the cerebrospinal fluid was clear. On section diffuse petechial haemorrhages were seen, mainly in the white matter. The right lung $(480 \mathrm{~g})$ and the left $(460 \mathrm{~g})$ were mildly congested. There was patchy bronchopneumonia in the upper left lobe. The heart $(240 \mathrm{~g})$ was normal in appearance. There were no visible changes on the valves, endocardium, or pericardium. The coronary arteries were patent. The digestive and genitourinary tracts were normal and so were the lymph nodes. The liver $(1520 \mathrm{~g})$ and spleen $(170 \mathrm{~g})$ were moderately enlarged, but there was no blackish discoloration.

\section{Case 2}

A 13-year-old African of the Lugbara tribe from Northern Uganda, who had been ill for two years, had progressively lost strength and become sleepy. One month before death he was admitted to a mental hospital where blood films were negative for trypanosomes. However, he developed insomnia and became aggressive and confused. A lumbar puncture showed 255 white blood cells, $65 \mathrm{mg} / 100$ $\mathrm{ml}$ protein, $45 \mathrm{mg} / 100 \mathrm{ml}$ sugar, but no trypanosomes. No trypanosomes were seen in the peripheral blood and no trypanocidal treatment was given. Two days before death he was transferred to the neurosurgical unit after a fall. On craniotomy there was no sign of raised intracranial pressure or haematoma.

Necropsy The boy weighed $32 \mathrm{~kg}$ and was $144 \mathrm{~cm}$ tall. He had multiple skin nodules on thighs, arms, left shoulder, and left foot. There were two temporal burr holes but no fracture or signs of infection. The brain was oedematous $(1380 \mathrm{~g})$ and the meninges showed capillary congestion. Two fresh haemorrhages were found on the orbital side of the frontal lobes. The lungs (both $450 \mathrm{~g}$ ) were oedematous and haemorrhagic. The heart $(180 \mathrm{~g})$ was flabby with patchy yellowish discoloration of the myocardium on section but there was no abnormality of the four chambers or the valves. Hookworms were present in the gastrointestinal tract. The liver $(1370 \mathrm{~g})$ and the spleen $(300 \mathrm{~g})$ showed a slight blackish colour on section. The cervical, hilar, mesenteric, and femoral lymph nodes were prominent.

\section{Histology}

The histology of the trypanosomal lesions was almost identical in both cases. Tissue was formalin fixed and paraffin embedded. The following stains were used: haematoxylin and eosin (HE), elasticaVan Gieson, Gram, Ziehl-Neelsen, periodic-acid Schiff (PAS), Giemsa, and Perl's stain.

Heart The general picture was that of a pancarditis with severe myocarditis, an endocarditis with occasional granulomata, a moderate but patchy epicarditis, a generalized valvulitis, and lesions of the conducting system.

The myocardium (Fig. 1) showed a diffuse interstitial or perivascular cuffing. The inflammatory cells consisted primarily of lymphocytes,

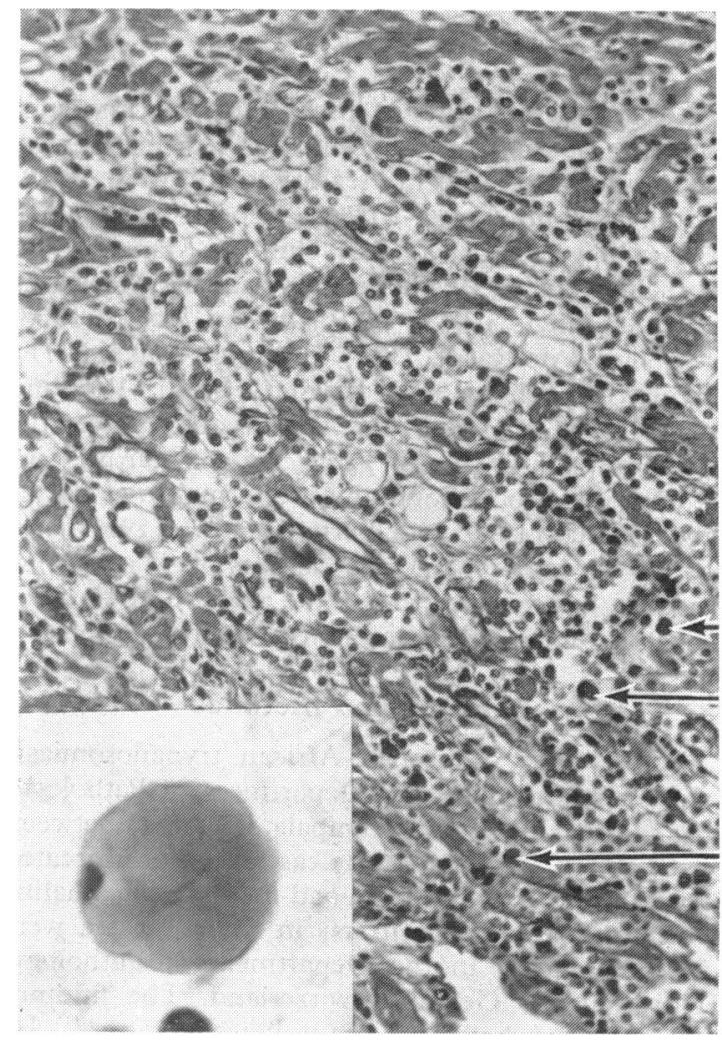

FIG. 1 Myocardial lesions in human African trypanosomiasis. Severe myocarditis with several morular cells (arrows): one is shown in the inset. (Case 2: $P A S \times 130$.) Inset: Case $1(H E \times 676)$. 

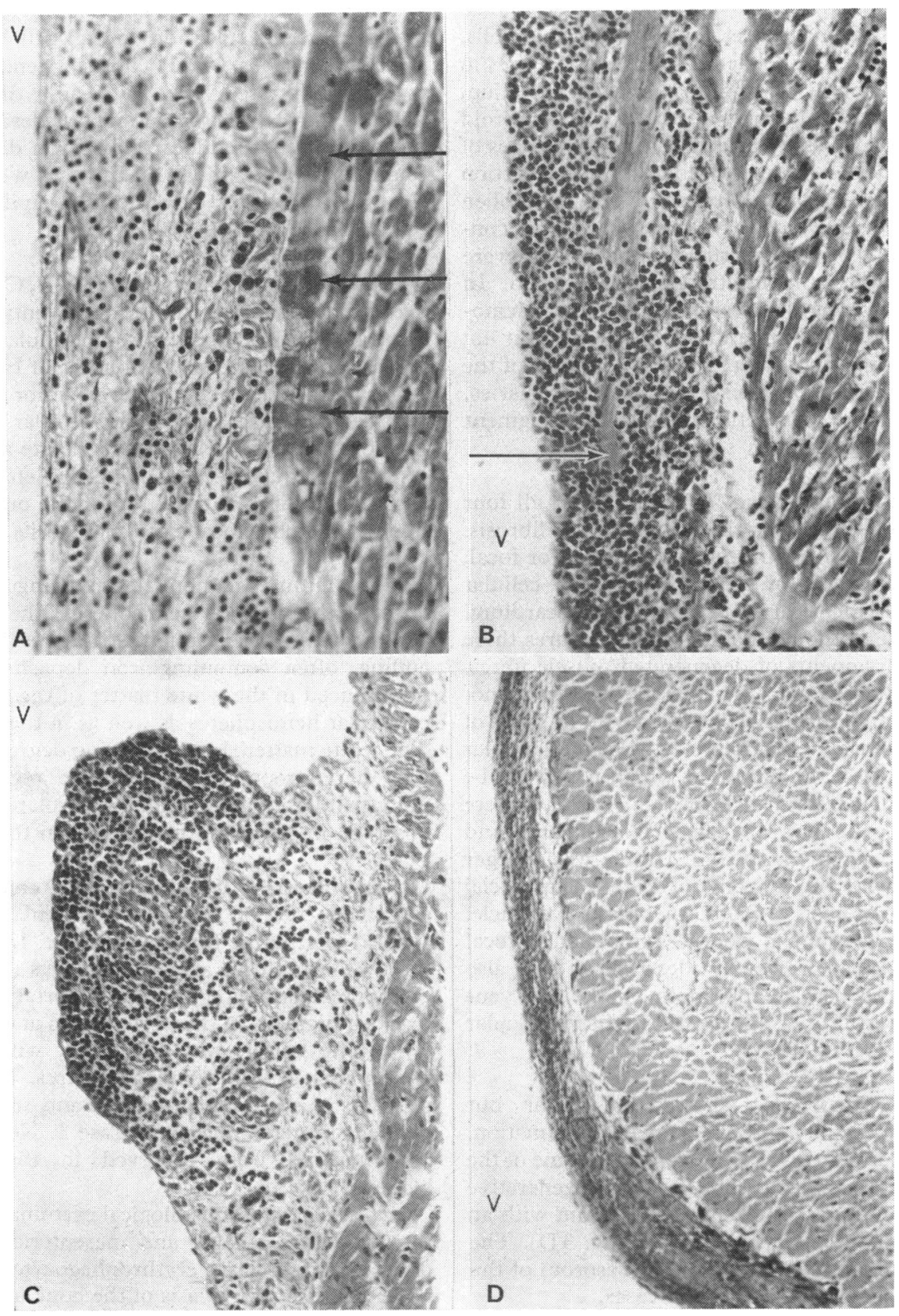

FIG. 2 Parietal endocarditis and mycocytolysis in human African trypanosomiasis. $V=$ ventricular chamber. (A) Superficial mycocytolysis showing contraction bands (arrows). Oedematous and fibrous thickening of the endocardium with chronic cellular infiltration. (Case 1: $H E \times 87$.) (B) Linear dense infiltration with fragmentation of muscle fibre which leads eventually to granuloma (arrow). (Case $2: H E \times 87$.) (C) Constituted granuloma with centrally degenerated muscle fibres. (Case $2: H E \times 87$.) (D) Fibrosing endocarditis. (Case $1:$ Elastica van Gieson $\times 33$.) 
mastocytes, plasma cells, morular cells, occasional Russell bodies, histiocytes, and Anitschkow cells. There was interstitial oedema. The muscle fibres in some areas showed varying phases of degeneration, sometimes with ballooning of the nuclei or ceroid degeneration of the cytoplasm. There were zones of patchy fibrosis with or without cellular reaction containing pre-existing capillaries with a swollen endothelium in places. Mycocytolysis and contraction bands of the superficial muscle fibres were seen underneath the infiltrated endocardium. In Case 1 the myocarditis was moderate and haemosiderin was found abundantly in histiocytes but not in muscle fibres; there were a few microfilaria of the Acanthocheilonema perstans type in the capillaries. In Case 2 there was little haemosiderin pigment but the myocarditis was severe.

The endocardium (Fig. 2A, B, C, D) in all four chambers showed patchy thickening and/or fibrosis. The chronic cellular infiltration was linear or focal, with the formation of granulomata. The cellular infiltrate was identical to that in the myocardium. In the centre of the granuloma-like structures there were often fragments of degenerated muscle fibres. There were no giant cells. These lesions were not seen in the myocardium. The histocytes in some of the granulomata contained cytoplasmic bipolar inclusion bodies, the nature of which could not be assessed. Small endocardial thrombi (Fig. 3A) were observed in the subvalvular, retropapillary, and intratrabecular region. In Case 1 there was a larger thrombus overlying a zone of recent superficial myocardial necrosis within the right ventricle. In Case 2, granulomata were less frequent. A focal endocarditis, as previously described, was also noticed in the pars membranosa on the left ventricular side in Case 1 and on the right ventricular side in Case 2 (Fig. 3B, C).

The epicardium also showed a similar but moderate and patchy chronic cellular inflammation. There was perineuritis and ballooning of some of the sympathetic ganglion cells with degenerative changes. In Case 2 a thickened epicardium with an occasional villous pattern was noted(Fig. $3 \mathrm{D}$ ). The coronary arteries as well as the vasa vasorum of the aorta were free of lesions in both cases.

Valves In sections from both atrioventricular valves and from the aortic and pulmonary cusps (Fig.4A, B, C, D) there was oedema and various degrees of ballooning of the valve with disorganization of the collagen fibres. Foci of chronic cellular inflammation were observed with occasional morular cells in the valve and at its insertion. The infiltration was linear or patchy and was mainly on the inflow of the atrioventricular and on the outflow side of the semilunar valves. The chordae tendineae were patchily infiltrated (Fig. 3C) and the papillary muscles showed the same lesions as described in the myocardium and endocardium. Iron deposits were found in all valves in Case 1 but they were absent in Case 2. In neither case did the capillaries reach the free portion of the valve.

The conducting system (Fig. 5A, B, C, D) showed dense fibrotic tissue in the atrioventricular node associated with a patchy chronic cellular infiltration in Case 1. In both cases the bundle of His was overrun by fibrotic bands and its superior portion was replaced by scar tissue, the cellular infiltration, including morular cells, was moderate at the origin of the right bundle-branch and the left branch was replaced by fibrous tissue. Near the origin of both bundle-branches focal calcium deposits were found.

Brain Diffuse, mononuclear meningoencephalitis affected the cerebral hemispheres, the cerebellum and the pontomesencephalic structures. Perivascular cuffing, often containing iron deposits, was most pronounced in the white matter of the cerebral and cerebellar hemispheres as well as in the brain stem. The white matter showed varying degrees of gliosis. The nerve roots of the pontine region showed monocellular inflammation. Morular cells were observed in the white matter and in the meninges.

Other organs The lungs were congested and contained foci of bronchopneumonia. The liver showed periportal fibrosis in Case 1. In Case 2 there were multiple schistosome eggs ( $S$. mansoni), granuloma formation and slight portal fibrosis, and blackish pigment in the portal tracts and in Kupffer cells. The spleen was congested, with moderate hyperplasia of the germinal centres. Some endophlebitis was present in Case 1 and some blackish pigment in macrophages in Case 2. No glomerular abnormalities were observed in the congested kidneys.

In Case 2 further histological examination showed the following: colonic and mesenteric lymphonodular schistosomiasis, erythrophagocytosis in lymph nodes, diffuse hyperplasia of the bone marrow without deposits of black pigment, chronic skin ulcers of unknown origin and normal adrenals.

\section{Retrospective study}

In the 8-year period (1967-1974) 7445 necropsies were carried out in the pathology department, Makerere. The sex ratio of the cases was, male to female, 7 to $3 ; 70$ per cent were 15 years old or 


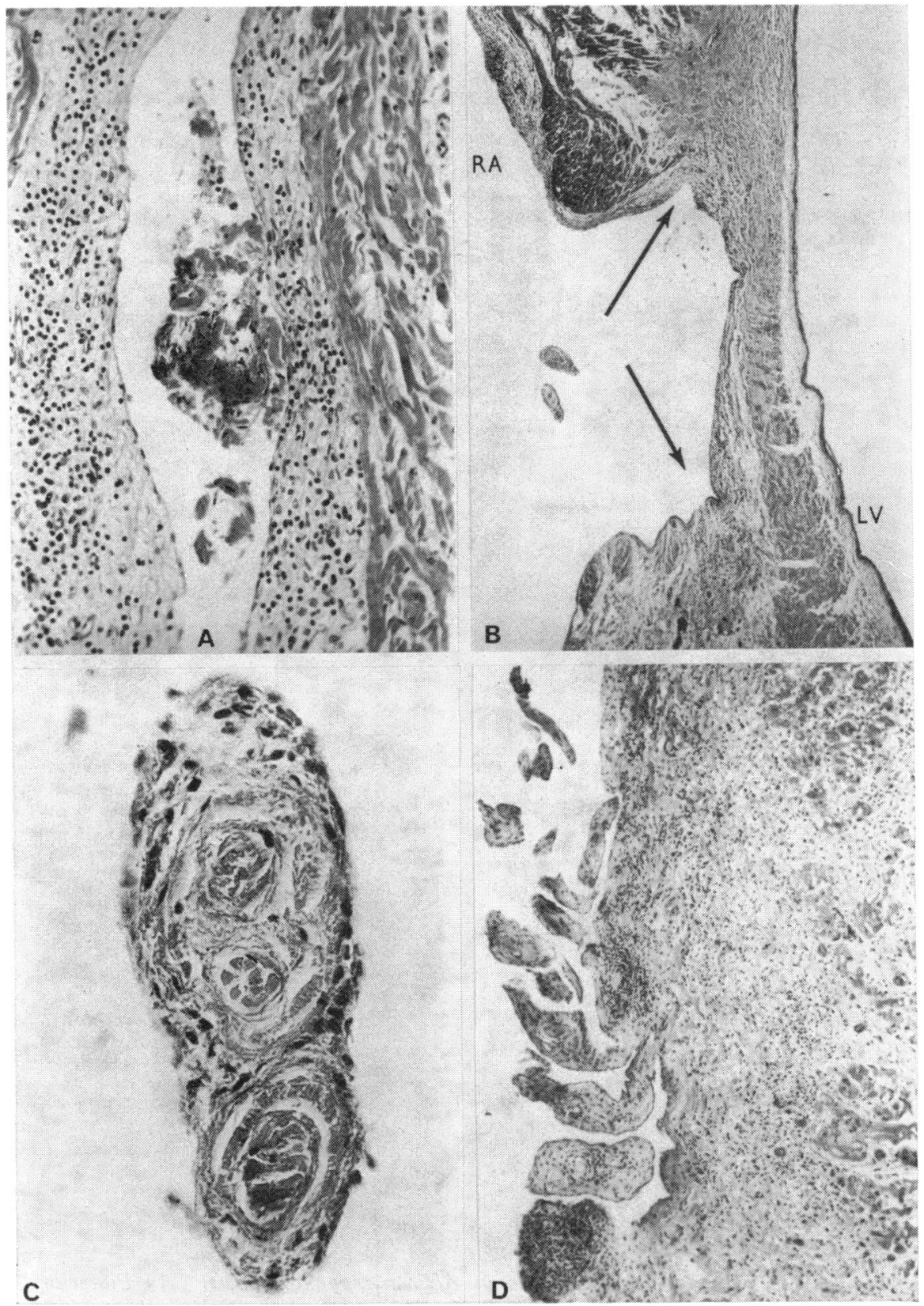

FIG. 3 Some special cardiac lesions in human African trypanosomiasis. (A) Endocardial thrombosis in intertrabecular space. (Case 1: HE $\times 87$.) (B) Pars membranosa showing plurifocal endocarditis (arrows). $L V=$ left ventricle; $R A=$ right atrium. (Case $2: H E \times 13$. (C) Magnified chorda tendinea of Fig. 3B showing chronic cellular infiltration. (Case 2: $H E \times 270$.) (D) Villous pericarditis. (Case 2:HE $\times 33$.) 

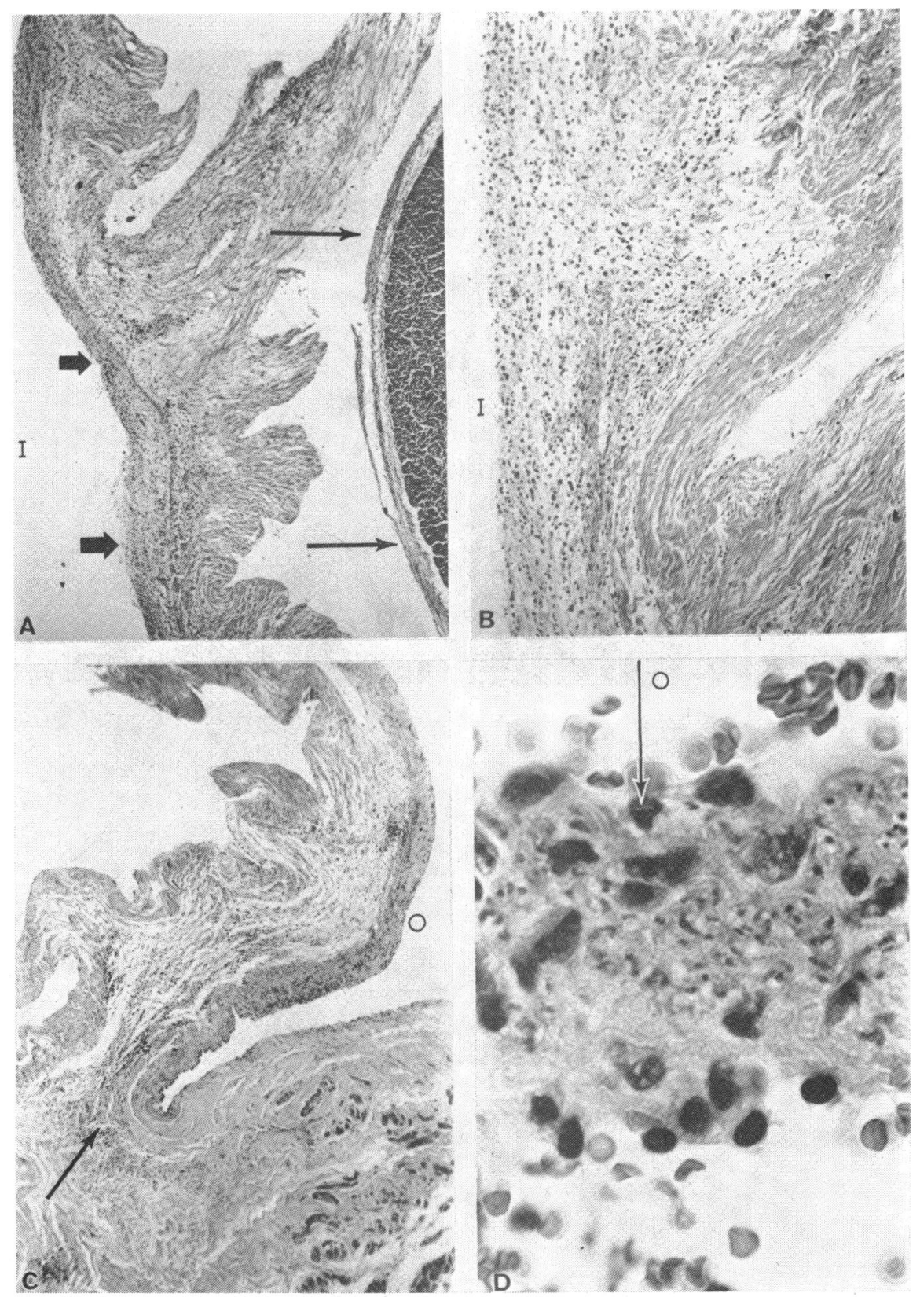

FIG. 4 (A-C) Valvular lesions in human African trypanosomiasis. (A) Posterior leaflet of mitral valve with multiple inflammatory foci (big arrows) predominantly on inflow side (I). Note retrovalvular parietal endocarditis (small arrows). (Case 2: $H E \times 13$.) (B) Posterior leaflet of mitral valve with oedematous and cellular inflammation, the latter mainly localized on inflow side (I). Disorganization of valvular fibres. (Case 2: $H E \times 33$.) (C) Pulmonary cusps with focal valvulitis predominantly localized on outflow side (O) and at insertion (arrow). (Case 1: HE $\times 13$.) (D) Cardiac valvular lesions in T.-brucei infected mouse. $O==$ outflow. Trypanosomal infiltration of pulmonary valve on outflow side. Mononuclear and polynuclear (arrow) infiltration. (HE $\times 670$.) 

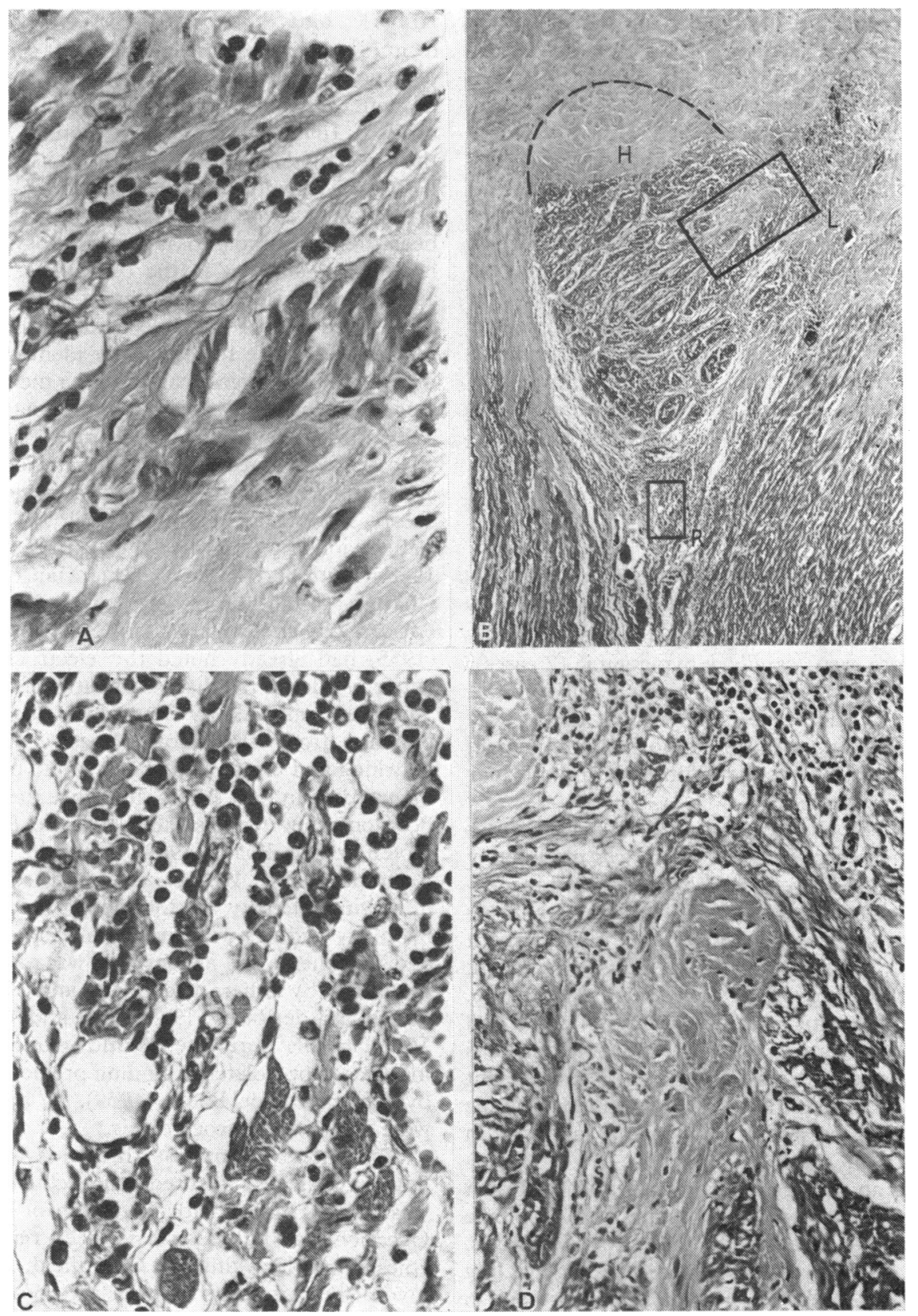

FI G. 5 Lesions of conducting system in human African trypanosomiasis. (A) Diffuse fibrosis and degeneration of atrioventricular node associated with foci of mononuclear infiltration. (Case 1:HE $\times 270$.) (B) Fibrous amputation of superior portion (broken line) of His bundle $(H)$ and portions of origin of left bundle-branch $(L) . R=$ origin of right bundle-branch. Squares indicating origin of bundle-branches as shown in Fig. 5C, 5D. (Case 2: $H E \times 13$.) (C) Right bundle-branch with degeneration of fibres and mononuclear infiltration. (Detail from Fig. 5B : $H E \times 270$.) (D) Left bundle-branch showing degeneration of fibres, invasive and dissecting sclerosis, as well as foci of chronic cellular infiltration. (Detail from Fig. 5B:HE $\times 106$.) 
more. Twelve cases of human trypanosomiasis were found among those aged over 15 years, so the incidence of trypanosomiasis in adults was 0.16 per cent. Histological findings were unavailable in 4 cases; therefore we report on only 8 of the cases. The findings in the 2 cases already described are excluded here; they are included in the Table.

Trypanosomes were found during life in 3 of the 8 patients and 2 died in spite of trypanocidal treatment. Trypanosomiasis was searched for but no parasites were found in the cerebrospinal fluid in the 5 other patients. The patients were all males aged from 13 to 45 years. All were Black Africans, 4 were of northern tribes (Lugbara), one a Dama from the Eastern Uganda, one a Tanzanian, one a Sudanese, and in 3 the tribe was not recorded. Three of the patients were initially admitted to a mental hospital.

\section{Necropsy}

The fresh brain weight in each of the 8 cases was above $1200 \mathrm{~g}$ except in one 18-year-old $(1160 \mathrm{~g})$ patient. The following macroscopical changes in the brain were seen: capillary hyperaemia ( 2 cases), thickening of the meninges ( 2 cases), and cerebral infarction (2 cases). Histologically there was perivascular cuffing with predominant lymphocytic, plasmocytic, and histiocytic infiltration and morular cells were present.

The weight of the heart in each case was within normal limits except for one, which was moderately hypertrophied $(380 \mathrm{~g})$. The valves appeared macroscopically normal in all cases. There was a chronic diffuse and focal myocarditis with predominant lymphocytic, plasmocytic, histiocytic infiltration. In 6 cases these changes were mild and in 2 moderate. Parietal endocarditis was found in 4 cases and morular cells in 1 case. In 1 heart a non-fibrinous valvulitis was seen. A chronic epicarditis was present in 7 cases and absent in 1 . An unexplained systemic embolism was seen in the brain in two cases and in the spleen in one case.

In 4 cases an enlarged spleen was associated with hepatic schistosomiasis, and in one case a splenic infarct was associated with parietal endocarditis. There was evidence in the hepatic histology of 'big spleen disease'. Bronchopneumonia was present in 7 cases, severely in 4 . No histological evidence of glomerular disease of the kidneys was found.

\section{Discussion}

Human trypanosomiasis is usually diagnosed by finding the parasite at the inoculation site, in lymph nodes, the peripheral blood, or, in the chronic stage, in the cerebrospinal fluid (Hutt,
Köberle, and Salfelder, 1973). Otherwise special techniques such as concentration by centrifugation, passage through sephadex columns, serology, immunofluorescence, or inoculation into animals are needed. In sleeping sickness from $T$. rhodesiense the direct evidence of the parasite is usually required before the potentially toxic trypanocidal treatment is given. African trypanosomes have scarcely ever been found in human tissue at necropsy, though the histological changes in the central nervous system are characteristic. In the present series 3 out of 10 cases were proved clinically and the lesions in the remaining 7 were histologically identical. Interestingly, 3 of the patients came from a mental hospital, a presentation stressed by Rwomushana (1973).

The histology of chronic meningoencephalitis in all cases was consistent with that classically described for cerebral human African trypanosomiasis (Mott, 1906; Laveran and Mesnil, 1912; Bertrand, Bablet, and Cicé, 1935; Calwell, 1937; van Bogaert 1958; Hutt and Wilks, 1971). Manson-Bahr and Charters (1963) described myocarditis in human African trypanosomiasis, and Schyns and Janssen (1955) had already noted the electrocardiographic abnormalities in the disease in patients from Zairea finding confirmed by Bertrand et al. $(1967 \mathrm{a}, \mathrm{b})$ in patients from the Ivory Coast. Histologically, Hawking and Greenfield (1941) noted trypanosomal myocarditis in East Africa, but since then there have been only few reports (de Raadt and Koten, 1968; Koten and de Raadt, 1969; Hutt and Wilks, 1971; Bertrand, 1974). In the present series myocarditis of varying intensity was found in every case in which histology findings were available (Table 1, Fig. 2A) and in general the appearance was similar to that described by others (de Raadt and Koten, 1968; Koten and de Raadt, 1969; Hutt and Wilks, 1971). Morular cells were often found within the cellular infiltration or isolated, a finding previously recorded by Koten and de Raadt (1969). In addition there were zones of mycocytolysis.

The endocardium was thickened and, in more advanced stages, fibrosed; the cellular infiltration was focal or linear with formation of granulomata. Occasional granulomata have been reported in the epicardium (Hawking and Greenfield, 1941) and the myocardium in cases of human African trypanosomiasis (Bertrand et al., 1967b) but not in the endocardium. In this series the granuloma formation consisted of central degenerate muscle fibres surrounded by histiocytes, in some of which there were cytoplasmic inclusion bodies suggestive of trypanosomal origin. In the immediate subendocardial region there often was an extensive myocytolysis similar to that observed in the rest of the myocardium. Acute mycocytolysis presenting with 
contraction bands is often referred to as MagariñoTorres lesion in human T. cruzi carditis (Andrade and Andrade, 1971) and may lead to myocardial granuloma formation (Andrade and Andrade, 1971; Hutt et al., 1973). Intimately associated with the endocardial lesions were microscopical thrombi, and these have also been recorded in human American trypanosomiasis (Köberle, 1968; Andrade and Andrade, 1971; McKinney, 1974), in endomyocardial fibrosis (Shaper, Hutt, and Coles, 1968) and in idiopathic cardiomegaly (Hutt, 1974). Systemic or pulmonary embolism is known to occur in human American trypanosomiasis (Andrade and Andrade, 1971) and in endomyocardial fibrosis (Shaper et al., 1968; Owor, 1973). Possibly the unexplained embolism in this series has its source in the endocardium. Apical aneurysms are known in human African trypanosomiasis (Laranja et al., 1956; Anselmi et al., 1966; Köberle, 1968; World Health Organization, 1969; McKinney, 1974) and they could be produced experimentally (Anselmi et al., 1971). To the best of our knowledge no aneurysms have been associated with human African trypanosomiasis; however, subvalvular aneurysms of unknown origin were described in Black Africans (Edington and Williams, 1968; Poltera and Jones, 1973). We found no aneurysms though the pars membranosa in 2 cases showed focal endocarditis which could have led eventually to aneurysms. Our series confirmed that trypanosomal pericarditis occurs in human African trypanosomiasis. Previous authors are agreed on this, though, curiously, d'Arbela et al. (1974) did not mention it in reporting 154 cases.

Although the heart valves appeared macroscopically normal, histology showed a focal or diffuse valvulitis present at the insertion as well as in the leaflets. Hutt and Wilks (1971) stated that the valves were not involved in human African trypanosomiasis and McKinney (1974) reported the same for human American trypanosomiasis. Ferreira and Rossi (1972), however, noted denervation of the valves in human Chagas disease. Valvulitis in human trypanosomiasis has probably been overlooked because of the normal macroscopical appearance and hence the lack of systematic analysis. The chordae tendineae of the atrioventricular valves were equally infiltrated and showed thickening. The papillary muscles showed identical lesions to the myocardium and endocardium, the retropapillary space being occasionally thrombosed. The retrovalvular endocardium of the atrioventricular valves showed an inflammatory infiltration.

Though endomyocardial fibrosis causes pancarditis it remains a cardiomyopathy of unknown origin, though the need for a more intensive search for a toxic or infective agent acting directly on the endocardium and myocardium has been emphasized (Farrer-Brown et al., 1972). Farrer-Brown and Tarbit (1972) showed the avascularity of the affected atrioventricular valves in endomyocardial fibrosis and they described for the first time the involvement of a pulmonary valve in this disease. Previously the semilunar valves were thought never to be involved (Edington and Gilles, 1969; McKinney, 1974). The association of endomyocardial fibrosis with subvalvular aneurysms has been recorded (Robertson and Jackson, 1960; Poltera and Jones, 1973). Armengaud and Diop (1960) reported cases of cardiomyopathy with heart failure from Senegal in which trypanosomes were identified in the blood and who responded to trypanocidal treatment. Similarly, Blackett and Ngu (1976) observed in the Cameroons congestive cardiomyopathies with an exceedingly high serlogical titre for trypanosomiasis.

Modifications in cardiac conduction and rhythm are often found in chronic and, to a lesser extent, acute human American trypanosomal carditis (Rosenbaum, 1964; Andrade and Andrade, 1971). Clinical reports on electrocardiographic abnormalities in African Gambian trypanosomiasis are uncommon (Bertrand et al., 1967a, b; Francis, 1972) and apparently almost non-existent in the Rhodesiense type. Lavier and Leroux (1939) described cardiac perineural cellular infiltration in one Congolese case and Bertrand et al. (1967b) showed a right bundle-branch block in one case from the Ivory Coast. In the present series multiple focal lesions were found in the conducting system in two hearts, either in the atrioventricular node, the bundle of His, or within the bundle-branches, and they presented as chronic cellular infiltrates including occasional morular cells or as fibrosing changes in or around the fibres of the conducting system. In both hearts both bundle-branches were involved. It is possible that an inflammatory involvement of the sinus node, similar to the lesions of the conducting system in this series, might contribute in human African trypanosomiasis to a sick sinus syndrome. Such a syndrome of unknown origin has recently been reported in young patients from Uganda (Ikeme, D'Arbela, and Somers, 1975).

Although African trypanosomes have only been once seen in a human heart (Hawking and Greenfield, 1941), there is old experimental evidence of their presence in trypanosomal myocarditis (Wolbach and Binger, 1912; Peruzzi, 1928; Regendanz and Hoeppli, 1929). In simian African trypanosomiasis Peruzzi (1928) showed leishmanoid forms in the myocardium, and Hoeppli and Regendanz 
(1930) differentiated the intravascular presence of flagellated trypanosomes in the heart and the extravascular presence of leishmanoid forms between the muscle fibres consisting of a trypanosome nucleus and a blepharoblast with scanty protoplasm. Similarly, Omerod and Venkatesan (1971a, b) confirmed the presence of amastigotes in the heart (1971b). However, no cystic forms were noticed, and this contrasts with the T. cruzi infection (World Health Organization, 1969). A review of the pathology of experimental trypanosomiasis (Losos and Ikede, 1972) and Murray et al. (1974a) did not mention endocardial valvulitis. Rats infected with $T$. brucei showed electrocardiographic abnormalities (Murray et al., 1974a), but the authors did not mention the conducting system nor did they state the arrhythmic change in the electrocardiogram. In mice infected with $T$. brucei we observed in the acute phase a severe valvulitis (Fig. 4D) and the usual pancarditis. 1 Trypanosomes in the valve were mainly on the flow side and there was subacute cellular infiltration, including red blood cells. Strikingly, the trypanosomes were found at the same site as the inflammatory foci in the present series. Lambert and Houba (1974), in experimentally infected mice, noted a disseminated vasculitis, and their immunological results suggested that immune complexes form in the blood as well as in the extravascular spaces, best seen in the target organs such as brain, heart, and kidney. But it was also shown experimentally in rats and in mice that the immune system was heavily depleted (Urquhart et al., 1973; Murray et al., 1974b, II).

To summarize, we conclude that human African trypanosomiasis is a generalized disease affecting the brain and the pancardium. It also affects the heart valves, the conducting system, and the sympathetic cardiac ganglia. The immune defence system is also affected, but the type of reaction seems to be time-dependent (Urquhart et al., 1973; Murray et al., 1974a). More research is needed to evaluate the possible aetiological role of human African trypanosomasis in the development of cardiomyopathies such as endomyocardial fibrosis and idiopathic cardiomegaly, particularly since trypanosomiasis has now a tricontinental (African, American, and Asian) distribution (Shrivastava and Shrivastava, 1974; Weinmann, 1974; Dissanaike, Ong, and Kan, 1974) and can occur as an imported disease (Spencer et al., 1975).

${ }^{1}$ The material was provided by $\mathrm{P}$. H. Lambert to whom we are grateful (WHO Research Unit, Hôpital cantonal, Geneva, Switzerland),

\section{References}

Andrade, Z. A., and Andrade, S. G. (1971). Chagas' disease (American trypanosomiasis). In Helminthic and Protozoal Diseases with Clinical Correlation, pp. 69-85. Ed. by H. Marcial Rojas. Williams and Wilkins, Baltimore.

Anselmi, A., Moleiro, F., Suarez, R., Suarez, J. A., and Ruesta, V. (1971). Ventricular aneurysms in acute experimental Chagas' myocardiopathy. Chest, 59, 654.

Anselmi, A., Pifano, F., Suarez, J. A., and Gurdiel, O. (1966). Myocardiopathy in Chagas' disease. I. Comparative study of pathologic findings in chronic human and experimental Chagas' myocarditis. American Heart fournal, 72, 469.

Armengaud, M., and Diop, B. (1960). Les gros coeurs isolés témoins d'une trypanosomiase. Africaine méconnue. Bulletins et Mémoires de la Faculté nationale de Médecine et de Pharmacie de Dakar, 8, 263.

Bertrand, E. (1974). Myocardites et cardiomégalies primitives. In Cardiovascular Disease in the Tropics, pp. 252-263. Ed. by A. G. Shaper, M. S. R. Hutt, and Z. Fejfar. British Medical Association, London.

Bertrand, E., Baudin, L., Vacher, R., Sentilhes, L., Ducasse, B., and Veyret, V. (1967a). Les signes cardio-vasculaires dans la trypanosomiase africaine. Médecine Tropicale, 27, 381.

Bertrand, E., Baudin, L., Vacher, P., Sentilhes, L., Ducasse, B., and Veyret, V. (1967b). Heart involvement in 100 cases of African trypanosomiasis caused by $\mathrm{T}$. gambiense. WHO/FAO Publication-Tryp/Inf/67, 24, 2-9.

Bertrand, I., Bablet, J., and Cicé, A. (1935). Lésions histologiques des centres nerveux dans la trypanosomiase humaine (A propos de 2 cas mortels non traités). Annales de l'Institut Pasteur, 54, 91.

Blackett, Kathleen, and Ngu, J. L. (1976). Immunological studies in congestive cardiomyopathy in Cameroon. British Heart Fournal, 38, 605.

Calwell, H. G. (1937). The pathology of the brain in rhodesian trypanosomiasis. Transactions of the Royal Society of Tropical Medicine and Hygiene, 30, 611,

D' Arbela, P. G., Patel, A. K., Grigg, L. G., and Somers, K. (1974). Pericarditis. In Cardiovascular Disease in the Tropics, pp. 58-69. Ed. by A. G. Shaper, M. S. R. Hutt, and Z. Fejfar. British Medical Association, London.

De Raadt, P., and Koten, J. W. (1968). Myocarditis in rhodensiense Trypanosomiasis. East African Medical Fournal, 45, 128 .

Dissanaike, A. S., Ong, H. T., and Kan, S. P. (1974). Trypanosome infections in Orang Aslis (Aborigines) in West Malaysia. Transactions of the Royal Society of Tropical Medicine and Hygiene, 68, 494.

Edington, G. M., and Gilles, H. M. J. (1969). Pathology in the Tropics, p. 311. Edward Arnold, London.

Edington, G. M., and Williams, A. O. (1968). Left atrial aneurysms associated with annular subvalvular left ventricular aneurysms. Fournal of Pathology and Bacterio$\log y, 96,273$.

Farrer-Brown, G., and Tarbit, M. H. (1972). Heart valve involvement in endomyocardial fibrosis. British Heart fournal, 34, 1062.

Farrer-Brown, G., Tarbit, M. H., Somers, K., and Hutt, M. S. R. (1972). Microvascular study of hearts with endomyocardial fibrosis. British Heart fournal, 34, 1250.

Ferreira, A. L., and Rossi, M. A. (1972). Uber die Denervierung des Herzens bei der Chagaskrankheit. Beitrage zur pathologischen Anatomie und zur allgemeinen Pathologie, $145,213$.

Francis, T. I. (1972). Visceral complications of Gambian trypanosomiasis in a Nigerian. Transactions of the Royal Society of Tropical Medicine and Hygiene, 66, 140 
Hawking, F., and Greenfield, J. C. (1941). Two autopsies on rhodesiense sleeping sickness; visceral lesions and significance of changes in cerebrospinal fluid. Transactions of the Royal Society of Tropical Medicine and Hygiene, 35, 155.

Hoeppli, R., and Regendanz, P. (1930). Beiträge zur Pathogenese und Histopathologie der Trypanosomeninfektionen der Tiere. Archiv für Schiffs-und Tropenhygiene, 34, 67.

Hutt, M. S. R. (1974). Idiopathic cardiomegaly. In Cardiovascular Disease in the Tropics, pp. 189-198. Ed. by A. G. Shaper, M. S. R. Hutt, and Z. Fejfar. British Medical Association, London.

Hutt, M. S. R., Köberle, K., and Salfelder, K. (1973). African trypanosomiasis. American trypanosomiasis. In Tropical Pathology, pp. 372-380, resp. 380-395. Ed. by H. Spencer. Springer Verlag, Berlin.

Hutt, M. R. S., and Wilks, N. E. (1971). African trypanosomiasis (sleeping sickness). In Helminthic and Protozoal Diseases with Clinical Correlation, pp. 57-68. Ed. by H. Marcial Rojas. Williams and Wilkins, Baltimore.

Ikeme, A. C., D'Arbela, P. G., and Somers, K. (1975). The sick-sinus syndrome in Africans. American Heart fournal, 89, 295.

Köberle, F. (1968). Chagas' heart disease: pathology. Cardiologia, 52, 82.

Koten, J. W., and de Raadt, P. (1969). Myocarditis in Trypanosoma rhodesiense infections. Transactions of the Royal Society of Tropical Medicine and Hygiene, 63, 485.

Lambert, P. H., and Houba, V. (1974). Immune complexes in parasitic diseases. In Progress in Immunology, 11, vol. 5, pp. 57-67. Ed. by L. Brent and J. Holborow. North Holland, Amsterdam.

Laranja, F. S., Dias, E., Nobrega, G., and Miranda, A. (1956). Chagas' disease: a clinical, epidemiologic and pathologic study. Circulation, 14, 1035.

Laveran, C. L. A., and Mesnil, F. (1912). Trypanosomes et Trypanosomiases, 2nd ed. pp. 725-728. Masson et Cie, Paris.

Lavier, G., and Leroux, R. (1939). Lésions cardiaques dans la maladie du sommeil. Bulletin de la Société de Pathologie Exotique, 32, 927-929.

Losos, G. J., and Ikede, B. O. (1972). Review of pathology of diseases in domestic and laboratory animals caused by trypanosoma congolense, $T$. vivax, $T$. brucei, $T$. rhodesiense and T. gambiense. Veterinary Pathology, 9, Suppl.

McKinney, B. (1974). Pathology of Cardiomyopathies, pp. 132 and 231. Butterworth, London.

Manson-Bahr, P. E. C., and Charters, A. D. (1963). Myocarditis in African trypanosomiasis. Transactions of the Royal Society of Tropical Medicine and Hygiene, 57, 119.

Mott, F. W. (1906). Histological observations on sleeping sickness and other trypanosome infections. Reports of Sleeping Sickness Commission, No. 7, pp. 5-45. John Bale, Sons \& Danielsson, London.

Mulligan, H. W., and Potts, W. H. (1970). The African Trypanosomiasis, p. 594. George Allen and Unwin, London.

Murray, M., Murray, P. K., Jennings, F. W., Fisher, E. W., and Urquhart, G. M. (1974a). The pathology of trypanosoma brucei infection in the rat. Research in Veterinary Science, 16, 77.

Murray, P. K., Jennings, F. W., Murray, M., and Urquhart, G. M. (1974b). The nature of immunosuppression in Trypanosoma brucei infections in mice. $I$. The role of the macrophages. II. The role of the $\mathrm{T}$ and $\mathrm{B}$ lymphocytes. Immunology, 27, 815 and 825.

Omerod, W. E., and Venkatesan, S. (1971). (a) The occult visceral phase of mammalian trypanosomes with special reference to the life cycle of Trypanosoma (trypanozoon) brucei. (b) An amastigote phase of the sleeping sickness trypanosome. Transactions of the Royal Society of Tropical Medicine and Hygiene, 65, 722 and 736.

Owor, R. (1973). Aortic embolism in endomyocardial fibrosis (EMF). African fournal of Medical Sciences, 4, 313.

Peruzzi, M. (1928). League of Nations Health Organization. Final report on human trypanosomiasis. Section 5, pp. 261-336.

Poltera, A. A., and Jones, A. W. (1973). Subvalvular left ventricular aneurysms. A report of 5 Ugandan cases. British Heart Fournal, 35, 1085.

Regendanz, P., and Hoeppli, R. (1929). Die Einwarderung der Trypanosomen in das Gewebe und die dadurch bewirkten histopathologischen Veränderungen. Archiv für Schiffsund Tropenhygiene, 33, 376.

Robertson, J. H., and Jackson, J. G. (1960). Cardiac aneurysms in Nigeria. Fournal of Pathology and Bacteriology, 80, 101.

Rosenbaum, M. B. (1964). Chagasic myocardiopathy. Progress in Cardiovascular Diseases, 7, 199.

Rwomushana, R. J. W. (1973). Necropsy findings in patients dying with mental illness. Uganda Medical fournal, 2, 51.

Schyns, C., and Janssen, P. (1955). Recherches électrocardiographiques dans la maladie du sommeil. Acta Cardiologica, 10, 26.

Shaper, A. G., Hutt, M. S. R., and Coles, R. M. (1968). Necropsy study of endomyocardial fibrosis and rheumatic heart disease in Uganda 1950-1965. British Heart fournal, 30, 391.

Shrivastava, K. K., and Shrivastava, G. P. (1974). Two cases of Trypanosoma (Herpetosoma) species infection of man in India. Transactions of the Royal Society of Tropical Medicine and Hygiene, 68, 143.

Spencer, H. C., Gibson, J. J., Brodsky, R. E., and Schultz, M. G. (1975). Imported African Trypanosomiasis in the United States. Annals of Internal Medicine, 82, 633.

Urquhart, G. M., Murray, M., Murray, P. K., Jennings, F. W., and Bate, E. (1973). Immunosuppression in Trypanosoma brucei infections in rats and mice. Transactions of the Royal Society of Tropical Medicine and Hygiene, $67,528$.

Van Bogaert, L. (1958). La trypanosomiase africaine. In Handbuch der speziellen pathologischen Anatomie und Histologie, Bd 13, 2er Teil, pp. 1086-1099. Ed. by O. Lubarsch, F. Henke, and R. Rössle. Springer, Berlin.

Weinmann, D. (1974). Trypanosomiasis in primates, human and subhuman, in India. Transactions of the Royal Society of Tropical Medicine and Hygiene, 68, 345.

Wolbach, S. B., and Binger, C. A. L. (1912). A contribution to the parasitology of trypanosomiasis. Fournal of Medical Research, 1912 to 1913, volume 27, 83.

World Health Organization (1969). Comparative studies of American and African Trypanosomiasis. World Health Organization. Technical Report Series, No. 411.

Requests for reprints to Dr. A. A. Poltera, Clinique universitaire de Médecine, Hôpital cantonal, 1211 Geneve 4, Switzerland. 